Research Article

\title{
Impact of R\&D\&I on the Performance of Spanish Construction Companies
}

\author{
Salvador López ${ }^{1}$ and Víctor Yepes $\mathbb{D}^{2}$ \\ ${ }^{1}$ School of Civil Engineering, Universitat Politècnica de València, Camino de Vera s/n, 46022 Valencia, Spain \\ ${ }^{2}$ Institute of Concrete Science and Technology (ICITECH), Universitat Politècnica de València, 46022 Valencia, Spain \\ Correspondence should be addressed to Víctor Yepes; vyepesp@cst.upv.es
}

Received 10 February 2020; Revised 9 July 2020; Accepted 11 July 2020; Published 26 July 2020

Academic Editor: Jinyang Xu

Copyright (C) 2020 Salvador López and Víctor Yepes. This is an open access article distributed under the Creative Commons Attribution License, which permits unrestricted use, distribution, and reproduction in any medium, provided the original work is properly cited.

\begin{abstract}
Deciding whether certain factors should be considered drivers of innovation in construction firms is crucial in terms of improving their performance and survival in an environment that is changing by leaps and bounds. Throughout the years, construction companies have been considered to be traditional and without the tendency to innovate. However, several studies have confirmed that this perception of the sector is evolving and that successful instruments from other industries are gradually being adapted for the benefit of the industry. The objective of this paper is therefore to investigate the potential factors affecting the performance of these organizations. Eighteen factors related to the individual, group, and organizational levels were identified through a review of the literature and an instrument developed that was validated by experienced professionals. A questionnaire was sent to 103 people working in the sector at the national level to obtain their views. The results of the classification analysis indicate that "technology and equipment" and "software acquisition" are considered the two most significant factors. In addition, these 18 factors can be classified into 7 groups: (i) internal drivers of innovation; (ii) innovation within the organization; (iii) technological innovation; (iv) technological links with the environment; (v) external drivers of innovation; (vi) innovation in processes; (vii) a culture of innovation in the company. Innovation in processes has the highest level of impact. This research deepens the current understanding of the factors at different organizational levels that must be highlighted in the implementation of an R\&D system in order for companies to improve their performance and survival in future processes.
\end{abstract}

\section{Introduction}

The traditional construction sector, which is made up of companies focused on infrastructure construction, has played a crucial role in the development of many countries' economies [1], despite periods of instability. The relevance of this sector has not been restricted to its direct effects on the economy but has been increased by the so-called "tractor effect" exerted by the sector on other economic activities, which doubles its total [2].

Recent years have seen an increase in studies that consider social aspects in multicriteria assessments of infrastructure. Aspects such as cohesion, culture, or research and innovation were unusual at the beginning of this century [3].
In the economic cycles of countries, there are factors that can have a negative impact on economic stability; the case of the construction industry in Spain is an instructive example, as a combination of factors including the decrease in housing demand after 2006, the "real estate bubble" that burst in 2007, the onset of the international financial crisis, and the sharp cuts in the budget for public infrastructure, aligned with the financial adjustment policies of the European Union (in which capital provisions were reduced by $74 \%$ between 2006 and 2011) [4], producing serious destabilizing effects that weakened the industry. However, since the first quarter of 2015, the sector has been reestablishing itself [5] and is now in a process of transformation in which axes such as digitalization, innovation, sustainability, and energy efficiency are reconfiguring traditional patterns. Adding that 
most infrastructures are designed to serve a significant group of people over a long, intergenerational period, the assessment of different dimensions of sustainability related to infrastructure design has been the focus of many researchers in recent times [6].

With regard to the situation of the construction companies, the sector shows a very dispersed business configuration, and $98.7 \%$ of all of these companies are SMEs. It is extremely important for the development of the construction industry that companies with between 50 and 249 workers begin to represent a higher percentage than their current level of just $1.2 \%$, since medium-sized and large companies are in general better able to withstand adverse economic circumstances, in addition to having better financing conditions and being more competitive. Small firms are hampered in their growth by a lack of access to finance, the risk of defaults, and the inability of most firms to expand into international markets. The labor market in the construction sector has seen a more accentuated loss of employment than the other sectors of the economy, meaning that the recovery of the workforce has been slower; in addition, with the emergence of new work systems linked to technological progress, the use of new materials and the optimization of production processes require an increasingly skilled and professional workforce. Another fundamental aspect of the labor market in this sector is the need to create a generational relay according to the demands of the environment, since it has been statistically shown that only $9 \%$ of workers in this field are under 30 years old, clearly demonstrating the aging of this sector [5].

There have been three significant published studies on the impact of different business strategies on construction innovation in firms or on projects. The theoretical bases of these were reviewed to inform the structure of the current research. The first previous study, undertaken in the Australian construction industry in 2006 [7], drew on a large-scale survey of the Australian construction industry. The nature of innovation competence was measured by four key innovation indicators: investment in R\&D, novelty of innovation, adoption of advanced practices, and the impact of innovation on the profitability/effectiveness of enterprises. This method, which focuses on "the innovation competence of repeat public sector clients," was developed to address problems in measuring innovation activity in other surveys. The results show that the clients have a relatively high level of innovation competence, compared to contractors, consultants, and suppliers.

The second previous study, undertaken in Spain, in 2012 [8], assessed the drivers, success factors, benefits, and barriers to innovation in a medium-size construction firm with a standardized innovation management system. As in the Australian study, there are coincidences in the client study, although it is seen from a different perspective. Whereas in Manley's study [7] clients were seen as drivers of innovation in the industry in Pellicer et al.'s 2012 [8] study, the client or contractor collected ideas that become innovation projects.
The third previous study, of the Spanish construction industry in 2014 [9], was founded on the validation of a model developed by a case study; this is focused on a medium-sized construction company which implemented and certified an innovation management system, as established by a Spanish standard.

This paper builds on these earlier contributions by examining the relative contribution of a more comprehensive range of internal and external strategies to innovation in the construction industry. It is based on the vision of the personnel of different hierarchy and age range obtaining an approach not only referring to managerial positions.

It is more immersed in the analysis of the internal and external factors of the organizations, adding additional perspectives for the construction sector in Spain.

\section{Literature Review}

Innovation enhances the competitive advantages of nations, industries, and companies [10]. Despite the innumerable definitions that exist for innovation, we emphasize the following aspects in this paper:

(1) The transformation of an old process [11]

(2) Carrying out activities in a different way

(3) The creation of new elements and processes for the market [12]

(4) The adoption of changes, seen from the perspective of novelty for the adopting organization

Although there are multiple definitions of $\mathrm{R} \& \mathrm{D}$, it is considered in this research to be creative work carried out in a systematic way, whose objectives are the creation of new knowledge or the use of existing knowledge adapted to one's own benefit. There are three main categories of $R \& D$, as follows:

(i) Basic research: the generation of new knowledge without a predetermined objective

(ii) Applied research: the obtaining of new knowledge with a predetermined objective

(iii) Experimental development: the creation of an original model that can be established as a prototype for future applications

The main aspect required for an activity to be considered $R \& D \& I$ is the systematic generation of new knowledge [13]. Innovation can be planned, organized, directed, and controlled by engineering managers in the same way as any other business activity in a project-based company [8].

Similarly, innovation can be classified as technological or organizational. The former has a technical or physical character that involves innovation in products or processes, while the latter is directed towards advanced business practices such as marketing and management [14].

If innovation is seen as a systematic search for opportunities [15] and is integrated into financial management and strategic planning, it is very possible that it will achieve a 
pronounced positive trend with respect to the organization, that is, the attainment of more stable trajectories [16-27].

In this sector and according to the OECD definition [14], organizational innovation is referred to as the application of new organizational methods and changes in business practices. It can be divided into three approaches, corresponding to business practices, site organization, and external relations with the company. In addition to this, organizational innovation can improve the capacity to generate, acquire, adapt, and use new knowledge, the ultimate goal of which is to raise the level of competitiveness of the organization. However, to ensure improvements in competitiveness, it is essential to have internal knowledge of the organization, experience in the training of personnel, and know-how about the organization and how interdepartmental information flows, including the objectives and criteria for social improvement [28].

A factor that is very closely linked to organizational innovation is the way in which processes are carried out, and it is evident that innovation in processes leads to an increased technical capacity to solve problems and develop more efficient processes [29]. This also applies to business management, which in the construction sector includes topics such as operational and strategic planning, financial management, total quality management, control, marketing, and knowledge management [30, 31].

The culture of innovation in an organization can be defined as the way in which the organization manages its work environment. This environment can be manifested as a complex combination of individuals and groups in which each has different assumptions, behaviors, and ideas, which change over time and are influenced by the institutions in the environment [32].

In summary, it represents the meaning of working in an organization [33]. It influences the commercial practices of companies and their knowledge management practices [34] and is recognized as a source of innovation and competitive advantage [35], provided that there is an exchange of knowledge including a space for creativity [30].

In order to strengthen the culture of innovation in a company, there needs to be collaboration between senior management and staff. Senior management stimulates the connection between innovation sources and organizational models, communication within the company, tolerance of errors in new practices, and staff participation through delegation of responsibilities; this causes the development and adaptation of innovation, skilled labor and skilled professionals, and increased productivity [36-38].

On the other hand, staff must be trained in order to be prepared for change and to generate lifelong learning processes [39]. At present, professional engineers are required to have more than the technical education acquired through their traditional Bachelor's degree programs. Employers who require their businesses to be well-managed demand this in order to achieve higher levels of productivity and quality. Skills such as leadership, management, communication, teamwork, and critical thinking are among those now required to be an effective professional engineer in a management position [31].

A culture of innovation generates intangible assets that can explain competitive business success, and vice versa $[40,41]$.

2.1. Innovation in the Construction Sector. In the construction sector, innovation is perceived as risky decision-making whose outcomes are dubious and complex in nature [42-45]; its purposes are determined for a single project and a single client [46]. The recovery of investments made for its implementation is significantly more complicated than in other sectors [47], and it has shown slower progress [48].

Most organizations consider their performance in terms of aspects that ensure their survival, such as the fulfillment of their mission, objectives, or goals, but since the 1970s, other variables have emerged that have been added to the analysis, such as morale, innovation, adaptability, and orientation to change [49]. Another characteristic inherent to the sector with respect to innovation is the marked influence that productivity and quality have on the final product $[50,51]$.

It has been shown that innovation in the construction sector is informal, unregistered, and tailor-made for specific projects $[9,52]$.

In spite of the delays and problems in the construction sector with reference to innovation, several reports have identified that innovation in construction is becoming the main competitive tool allowing companies to penetrate the market and increase profitability [53], without forgetting the importance of social factors by including innovative concepts in infrastructure design [6]. Companies in the construction sector undoubtedly constitute a great challenge for research into management and innovation [54].

\section{Materials and Methods}

This research was based on a review of the literature, an analysis of innovation surveys applied generally to both the productive sector and the construction sector, and a questionnaire on data collection. Among the questions considered, seven (questions 19-25) were adapted and modified from an existing questionnaire developed by INE [55] and ENIT [13]; this questionnaire was adapted because both surveys measure innovation in the industry in general, on the one hand from Argentina and on the other from Spain, so the questions closely matched the purpose and context of this study. An additional eleven questions were developed based on a literature review and then added to the questionnaire to further capture the characteristics of the innovation orientations.

The first stage of the research identified the current state of the construction industry in Spain, its links with economic and political fluctuations, and the repercussions of innovation activities in these companies. Following this search process, 18 factors at individual, group, and organizational levels were identified from the selected final articles, as summarized in Table 1. 
TABLE 1: Factors at the individual, group, and organizational levels.

\begin{tabular}{|c|c|c|c|}
\hline Number & Factor & Description & Sources \\
\hline 9 & Knowledge transfer & Transfer of project learning to ongoing business practices & {$[54]$} \\
\hline 10 & Motivation & Highly motivated working teams & {$[56]$} \\
\hline 11 & Public policy instruments & $\begin{array}{l}\text { Public policy instruments that promote R\&D such as incentives to revalue } \\
\text { scores in bids, use of new methodologies (BIM), tax reductions, and subsidies }\end{array}$ & {$[57]$} \\
\hline 12 & Feedback cycles & Feedback cycles at various stages of innovation & {$[58-62]$} \\
\hline 13 & Technology and equipment & Technology and equipment such as tools, equipment, and heavy machinery & {$[63]$} \\
\hline 14 & Influence of the client & $\begin{array}{c}\text { Influence of the client such as his or her requirements, competence, and level of } \\
\text { sophistication }\end{array}$ & {$[7,54,57,64-66]$} \\
\hline 15 & $\begin{array}{l}\text { Recruitment of new } \\
\text { graduates }\end{array}$ & Recruitment of new graduates & {$[61]$} \\
\hline 16 & Collaboration & Staff collaboration, cooperation, and camaraderie & {$[49]$} \\
\hline 17 & External influences & $\begin{array}{c}\text { External influences such as contractors, trade unions, employers, and trade } \\
\text { associations }\end{array}$ & {$[67,68]$} \\
\hline 18 & Customer satisfaction & Quality management systems focused on customer satisfaction & {$[46,69]$} \\
\hline 19 & Internal sources & $\begin{array}{c}\text { Internal sources of information such as groups of companies, departments, and } \\
\text { workers }\end{array}$ & {$[55]$} \\
\hline 20 & $\begin{array}{l}\text { Construction market } \\
\text { sources }\end{array}$ & $\begin{array}{l}\text { Construction market sources such as competitors or other companies in the } \\
\text { same field }\end{array}$ & \\
\hline 21 & Education and research & $\begin{array}{c}\text { Sources of education and research such as universities or other institutions of } \\
\text { higher education }\end{array}$ & \\
\hline 22 & $\begin{array}{l}\text { Professional and industry } \\
\text { associations }\end{array}$ & $\begin{array}{c}\text { Professional and sector associations such as chambers of commerce and } \\
\text { engineering colleges }\end{array}$ & \\
\hline 23 & Software acquisition & $\begin{array}{l}\text { Acquisition of software to meet current demands with appropriate tools } \\
\text { Contracting technology such as the acquisition of rights to use patents, }\end{array}$ & [13] \\
\hline 24 & Contracting technology & $\begin{array}{c}\text { nonpatented inventions, licenses, trademarks, designs, know-how, technical } \\
\text { assistance, or technological services }\end{array}$ & \\
\hline 25 & R\&D personnel & Formally established R\&D personnel in the company & \\
\hline 26 & $\begin{array}{l}\text { Decentralized } \\
\text { organizations }\end{array}$ & $\begin{array}{c}\text { Decentralized organizations, often referred to as "skunkworks." These refer to } \\
\text { organizations with a high degree of autonomy, in which a small and structured } \\
\text { group of people work on researching and developing a project mainly for the } \\
\text { sake of innovation }\end{array}$ & {$[70,71]$} \\
\hline
\end{tabular}

The second stage of the investigation included three phases: the creation of a survey with a five-point Likert scale, a pilot test, and the dissemination of the survey. The target population was mostly experienced personnel from the construction industry in administrative and field positions at different levels of the organization.

A pilot study was carried out with 10 middle or senior managers from different companies to check the relevance of the questions and to identify any ambiguity in the wording of the questions. Based on their suggestions, the questionnaire was revised to improve its accuracy and readability. In the final questionnaire, a five-point Likert scale was used to measure the respondents' opinions on the influence of each factor ( $1=$ very low impact, $3=$ moderate impact (neither low nor high), and $5=$ very high impact).

In this study, two methodologies were used to collect information. In the first instance, a nonprobability sampling was carried out for the sake of convenience, due to the lack of a sampling frame favorable for the application of random sampling. The participants were drawn from companies that could be identified through the SABI platform (in which identification is based on e-mail, telephone, etc.) and who voluntarily agreed to respond to the survey by e-mail.

The resulting sample included 94 companies, obtained by proposing to manage a $95 \%$ confidence level, a $6 \%$ estimation error, and a $10 \%$ probability that the event under study will occur.
After four months of data collection, information gathered from 103 companies was used in the final data analysis. The profiles of the respondents are shown in Table 2.

\section{Results and Discussion}

The reliability of the measuring instrument was measured by calculating Cronbach's alpha. This involves obtaining the total percentage of the variance of the indicators attributable to the construct.

In order to determine the extent to which the correlation levels are reliable, we can analyze the correlation coefficients; the closer these values are to one, the higher the internal consistency and reliability of the instrument are.

SPSS statistical software was used to evaluate the reliability of the measuring instrument based on Cronbach's alpha. This application allows us to determine the values associated with each of the indicators and to examine how much they would vary if any of these indicators were eliminated. It is therefore a useful tool for determining whether it is possible to improve the reliability of the proposed measurement instrument by eliminating any of the indicators that do not have sufficient levels of correlation with the construct to which they are associated. This process is especially useful for debugging scales by eliminating items that are not suitable for measuring the constructs [72]. 
TABLe 2: Profiles of respondents.

\begin{tabular}{|c|c|c|c|}
\hline Characteristic & Categorization & Number & $\%$ \\
\hline \multirow{5}{*}{ Profession } & Civil engineer & 33 & 32.0 \\
\hline & Road, canal, and port engineers & 19 & 18.4 \\
\hline & Architect & 30 & 29.1 \\
\hline & Economist/financial & 5 & 4.9 \\
\hline & Others (specify)* & 16 & 15.5 \\
\hline \multirow{4}{*}{ Age } & $23-30$ & 12 & 11.7 \\
\hline & $31-40$ & 28 & 27.2 \\
\hline & $41-50$ & 47 & 45.6 \\
\hline & Over 51 & 16 & 15.5 \\
\hline \multirow{2}{*}{ Gender } & Male & 81 & 78.6 \\
\hline & Female & 22 & 21.4 \\
\hline \multirow{3}{*}{ Level of education } & Graduate degree & 34 & 33.0 \\
\hline & Master's degree & 64 & 62.1 \\
\hline & Others (specify)** & 5 & 4.9 \\
\hline \multirow{9}{*}{ Position in the firm } & Manager & 4 & 3.9 \\
\hline & Technical services & 4 & 3.9 \\
\hline & Scholars & 4 & 3.9 \\
\hline & Director of R\&D\&I department/quality & 5 & 4.9 \\
\hline & Plant headquarters & 9 & 8.7 \\
\hline & Head of administrative services & 14 & 13.6 \\
\hline & Director & 15 & 14.6 \\
\hline & Head of technical services & 20 & 19.4 \\
\hline & Construction manager & 28 & 27.2 \\
\hline \multirow{4}{*}{ Type of company } & Supplier (materials; inputs) & 2 & 1.9 \\
\hline & Consultancy (studies; designs) & 24 & 23.3 \\
\hline & Construction & 72 & 69.9 \\
\hline & Others ${ }^{* * *}$ & 5 & 4.9 \\
\hline \multirow{4}{*}{ Company size } & Medium (51 to 200 workers) & 18 & 17.5 \\
\hline & Small (11 to 50 workers) & 25 & 24.3 \\
\hline & Microcompany (up to 10 workers) & 26 & 25.2 \\
\hline & Large company (more than 200 workers) & 34 & 33.0 \\
\hline \multirow{6}{*}{ Years of company experience } & 2 to 5 years & 7 & 6.8 \\
\hline & Less than 2 years & 15 & 14.6 \\
\hline & More than 30 years & 18 & 17.5 \\
\hline & 5 to 10 years & 20 & 19.4 \\
\hline & 20 to 30 years & 21 & 20.4 \\
\hline & 10 to 20 years & 22 & 21.4 \\
\hline
\end{tabular}

${ }^{*}$ Others = technician, industrial engineer, environmental engineer, and accountant. ${ }^{* *}$ Others=vocational training/technical engineering. *** Others = promotion company/road maintenance/signaling company.

4.1. Ranking of Factors. The value of Cronbach's alpha was 0.843, which is much higher than the threshold of 0.70 [73], and this implies high reliability for the data. As shown in Table 3, the mean scores for the 18 factors range from 3.845 to 2.738 . To select the critical factors, the normalized values of the mean scores were calculated. The same method was applied by $\mathrm{Xu}$ et al. [74] and Zhao et al. [75], who determined that the critical factors were those with normalized values of 0.50 or more. This principle was applied here, and factors with mean scores closest to the maximum mean of all factors are therefore considered critical. Thirteen of the 18 factors have normalized values greater than 0.50 and are therefore considered critical (Table 3 ).

Of these, "technology and equipment" was ranked first, indicating that each member of the group knew and had a favorable opinion on this factor, considering it to be paramount and to have a high impact. "Software acquisition" was ranked second, indicating that almost all respondents believe that this factor represents an important source of innovation.

The perception of a "decentralized organization," also referred to as a skunkworks project, was ranked in the last place. This factor is therefore the least important, and this was confirmed by an analysis of the answers obtained. The main reason for this may be that the traditional type of structure in this sector has worked in a different way over time, and the use of a structure with these characteristics is unfamiliar and unimportant.

4.2. Exploratory Factorial Analysis. This is a multivariate method that makes it possible to associate variables that are strongly correlated with each other, and whose correlations with the variables of other conglomerates are smaller [76]. It 
TABLE 3: Ranking of the factors.

\begin{tabular}{|c|c|c|c|c|}
\hline Number & Factors & Mean value & Rank & Normalization $^{\mathrm{a}}$ \\
\hline 9 & Knowledge transfer & 3.544 & 8 & 0.73 \\
\hline 10 & Motivation & 3.583 & 5 & 0.76 \\
\hline 11 & Public policy instruments & 3.233 & 15 & 0.45 \\
\hline 12 & Feedback cycles & 3.369 & 12 & 0.57 \\
\hline 13 & Technology and equipment & 3.845 & 1 & 1.00 \\
\hline 14 & Influence of the client & 3.680 & 4 & 0.85 \\
\hline 15 & Recruitment of new graduates & 3.039 & 16 & 0.27 \\
\hline 16 & Collaboration & 3.718 & 3 & 0.89 \\
\hline 17 & External influences & 3.485 & 9 & 0.68 \\
\hline 18 & Customer satisfaction & 3.476 & 10 & 0.67 \\
\hline 19 & Internal sources & 3.398 & 11 & 0.60 \\
\hline 20 & Construction market sources & 3.573 & 7 & 0.75 \\
\hline 21 & Education and research & 3.291 & 13 & 0.50 \\
\hline 22 & Professional and industry associations & 3.282 & 14 & 0.49 \\
\hline 23 & Software acquisition & 3.816 & 2 & 0.97 \\
\hline 24 & Contracting technology & 3.583 & 6 & 0.76 \\
\hline 25 & $\mathrm{R} \& \mathrm{D}$ personnel & 2.825 & 17 & 0.08 \\
\hline 26 & Decentralized organizations & 2.738 & 18 & 0.00 \\
\hline
\end{tabular}

${ }^{\mathrm{a}}$ Normalized value $=($ mean - minimum mean $) /($ maximum mean - minimum mean $)$

is therefore used to analyze the underlying groupings among the 18 identified factors involved. The ratio between the sample size and the number of factors is 5.72 .

The factorability of the correlation matrix is tested using the Kaiser-Meyer-Olkin Index (KMO) (KMO $\geq 0.50)$. This statistical analysis gives values of between zero and one, where figures close to zero (or substantially less than 0.5) give information about the inconvenience of using an exploratory factorial analysis.

Bartlett's sphericity test, which identifies the presence of correlation between the variables analyzed, also allows us to determine the convenience of using factorial analysis by assessing the null hypothesis with the usual significance level of $0.05 \%$. This assumes that the correlation matrix is equal to the identity matrix and would indicate that the variables are not correlated.

The communalities indicate the percentage variance of each of the analyzed items that is explained by the set of factors; in other words, they refer to the common variance among the different variables and are widely used in common factorial analysis [77]. Values lower than 0.5 imply that the level of explanation of the model by the variable in question does not reach sufficient levels and the variable should be dispensed with if it is of little importance in relation to the objectives set out in the research. SPSS was used to carry out the exploratory factorial analysis, through which it is possible to obtain the different matrices, statistics, and adjustment measures that will allow the validity of the different scales to be examined in relation to each of the constructs analyzed [72].

The KMO value is 0.785 , indicating a high degree of common variance between the factors. The result of Bartlett's sphericity test is 528.671 , with a significance of 0.000 , indicating that the population correlation matrix is not an identity matrix. The data are therefore appropriate for principal component analysis (PCA).
An analysis of the main components was carried out to identify the groupings of underlying factors, resulting in the extraction of seven groupings with eigenvalues very close to one. These seven groups of factors explain $69.76 \%$ of the variance (as shown in Figure 1 and Table 4); a minimum of $60 \%$ is typically used for the extraction of the factors [78]. Table 5 presents the groupings based on varimax rotation. The factorial load value represents the contribution of the individual factors to each underlying cluster, and all factorial load values exceed the value of 0.45 recommended by Comrey and Lee [79].

Table 6 gives a summary of the analysis of variance (ANOVA) results.

4.2.1. Internal Drivers of Innovation. The primary reasons perceived by respondents as having the greatest impact on company performance are related to internal drivers of innovation. This grouping comprises three factors: (i) highly motivated work teams; (ii) quality management systems focused on customer satisfaction; and (iii) internal information sources.

These factors reflect the influence of strategic and organizational values concerning the company structure. In other words, they represent organizational changes that influence the external environment [80].

The factors affecting motivation in work teams can be classified into (i) positive work environments; (ii) the ability of staff to perform their work; (iii) and incentives received from management [81]. A combination of these factors can reduce the obstacles to innovation in processes [56]. The results of the survey put this factor in the fifth place (see Table 3, ranking of factors).

Motivation is associated with the idea of a purpose that a work team seeks to achieve. From the authors' point of view, the motivation at individual and collective level is a determining factor for companies' success and competitiveness. 


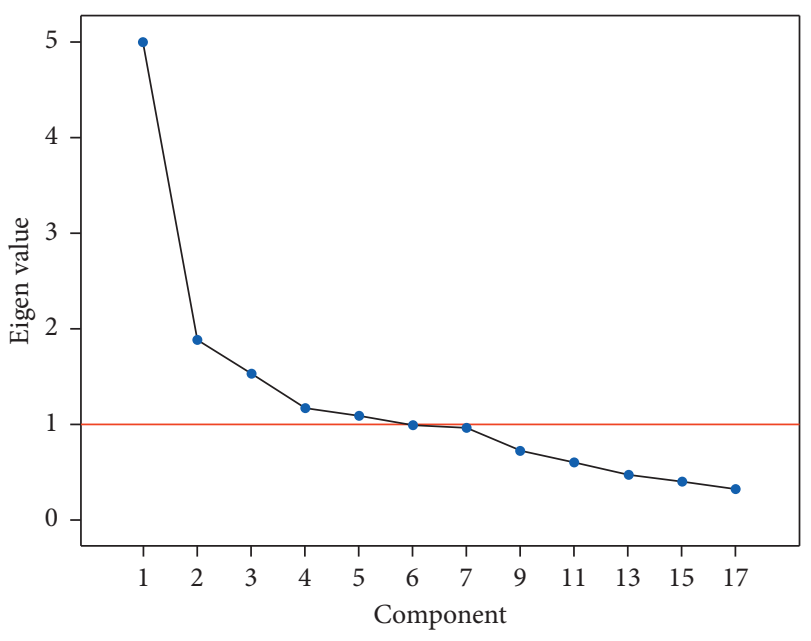

Figure 1: Screen plot of the PCA.

TABLE 4: Total variance explained for factors.

\begin{tabular}{lccc}
\hline Groupings & Total & $\begin{array}{c}\text { Initial eigenvalues } \% \text { of } \\
\text { variance }\end{array}$ & Cumulative \% \\
\hline 1 & 4.992 & 27.735 & 27.735 \\
2 & 1.871 & 10.396 & 38.132 \\
3 & 1.519 & 8.44 & 46.572 \\
4 & 1.163 & 6.461 & 53.033 \\
5 & 1.082 & 6.011 & 59.044 \\
6 & 0.979 & 5.441 & 64.485 \\
7 & 0.949 & 5.271 & 69.755 \\
$\ldots$ & $\ldots$ & $\ldots$ & $\ldots$ \\
17 & 0.306 & 1.702 & 98.586 \\
18 & 0.255 & 1.414 & 100.000 \\
\hline
\end{tabular}

Quality management systems focusing on customer satisfaction have been booming in recent years, at least in the SMEs in this sector $[46,69]$.

It is important to define the client in an independent way, as he or she is a very important factor in the innovation and marketing process. Marketing processes are strongly correlated with quality management systems based on customer satisfaction, an aspect that deserves more attention [82]. It appears that, in order to remain competitive in the market, organizations should make sure their customers' expectations are properly met by developing new or improved products/processes or services and delivering the construction output within cost, time, and quality parameters.

In summary, what stands out in this section is that customers are increasingly focusing on quality and avoiding building repairs $[50,51]$, and if a customer is satisfied, the other interested parties will also be satisfied. Although this factor is increasing in importance, it is ranked in the tenth place.

With regard to internal information sources, it is determined that it is possible to improve both the competencies among interdepartmental collaborators and the performance of the company [8].
4.2.2. Innovation within the Organization. Surprisingly, innovation within the organization was a secondary factor in this analysis. This cluster explains $10 \%$ of the total variability and comprises three factors: (i) sources of education and research; (ii) staff dedicated to research and development, in units or departments that are specifically focused on these activities in a formal way; and (iii) the creation of decentralized organizations (skunkwork projects). This grouping represents the existing links between companies or educational centers and the formal establishment of R\&D departments, in which people dedicated research and development work in units or departments specifically to these activities. Decentralized skunkwork projects are small groups or organizations with a high degree of autonomy who carry out the functions of researching, developing, marketing, and producing new projects and products for the sake of innovation [70, 71, 83]. Moreover, these projects promote economic well-being, and they may complement many social interventions as well [84].

One obvious fact is that two of the components of this cluster, the creation of decentralized organizations and the formal establishment of R\&D departments within the organization, have the lowest levels of impact on business performance, as rated by respondents. This is due to a lack of familiarity and knowledge of these items by respondents.

4.2.3. Technological Innovation. This comprises two factors: (i) technology and equipment and (ii) technology related to contracting. Equipment-related technology was identified by the respondents as the most important factor that produces a significant impact on the performance of organizations.

The most representative form or at least showing tangible results that influence the productivity of the companies is the technology in the equipment. In this document, it has not been the exception since it is positioned as the factor of greater impact according to the results obtained.

Concisely, to examine how the different mechanisms of equipment technology change have influenced the productivity in the sector, we can use two factors as examples: information processing and ergonomics.

Information processing: over time, construction equipment has been designed to provide greater and more accurate information regarding internal and external processes.

Ergonomics: it is defined as technology that alleviates physical stresses imposed by the work environment on the human operator.

This result aligns with the work done by Goodrum and Haas [63], in which equipment and technology were found to be key factors in the long-term improvement of productivity.

Contracting-related technology refers to the acquisition of rights to use patents, unpatented inventions, licenses, trademarks, designs, know-how, technical assistance, or technological services. The respondents considered this to be the sixth most important factor. 
TABLE 5: Grouping matrix after varimax rotation.

\begin{tabular}{|c|c|c|c|c|c|c|c|c|}
\hline \multirow{2}{*}{ Number } & \multirow{2}{*}{ Factors } & \multicolumn{7}{|c|}{ Grouping } \\
\hline & & $\mathrm{i}$ & ii & iii & iv & $\mathrm{v}$ & vi & vii \\
\hline 10 & Motivation & 0.644 & - & - & - & - & - & - \\
\hline 18 & Customer satisfaction & 0.806 & - & - & - & - & - & - \\
\hline 19 & Internal sources & 0.584 & - & - & - & - & - & - \\
\hline 21 & Education and research & - & 0.498 & - & - & - & - & - \\
\hline 25 & R\&D personnel & - & 0.763 & - & - & - & - & - \\
\hline 26 & Decentralized organizations & - & 0.733 & - & - & - & - & - \\
\hline 13 & Technology and equipment & - & - & 0.757 & - & - & - & - \\
\hline 24 & Contracting technology & - & - & 0.710 & - & - & - & - \\
\hline 22 & Professional and industry associations & - & - & - & 0.764 & - & - & - \\
\hline 23 & Software acquisition & - & - & - & 0.742 & - & - & - \\
\hline 11 & Public policy instruments & - & - & - & - & 0.599 & - & - \\
\hline 14 & Influence of the client & - & - & - & - & 0.504 & - & - \\
\hline 17 & External influences & - & - & - & - & 0.753 & - & - \\
\hline 20 & Construction market sources & - & - & - & - & 0.534 & - & - \\
\hline 9 & Knowledge transfer & - & - & - & - & - & 0.767 & - \\
\hline 12 & Feedback cycles & - & - & - & - & - & 0.543 & - \\
\hline 15 & Recruitment of new graduates & - & - & - & - & - & - & 0.745 \\
\hline 16 & Collaboration & - & - & - & - & - & - & 0.646 \\
\hline
\end{tabular}

Notes. Grouping names: i: internal drivers of innovation; ii: innovation within the organization; iii: technological innovation; iv: technological links with the environment; v: external drivers of innovation; vi: innovation in processes; vii: culture of innovation within the company.

TABLE 6: Summary of ANOVA results.

\begin{tabular}{lcccccc}
\hline \multirow{2}{*}{ Categories } & \multicolumn{3}{c}{ Principal components } & vi & vii \\
\hline Profession & i & ii & iii & iv & v & N.S \\
Age & $P=0.028$ & N.S & N.S & $P=0.029$ & N.S & $P=0.04$ \\
Gender & N.S & N.S & N.S & $P=0.009$ & N.S & N.S \\
Level of education & N.S & N.S & N.S & N.S & N.S & N.S \\
Position in the firm & N.S & N.S & N.S & N.S & N.S & N.S \\
Type of company & N.S & N.S & N.S & N.S & N.S & N.S \\
Company size & N.S & N.S & N.S & N.S & N.S & N.S \\
Years of company experience & N.S & N.S & N.S & N.S & N.S & N.S \\
\hline
\end{tabular}

Note. N.S. = not significant.

4.2.4. Technological Links with the Environment. This grouping explains $6 \%$ of the total variability, comprising two factors: (i) professional and industry associations and (ii) software acquisition.

Professional and sectoral associations, which act as links between companies in the sector, involve collaboration agreements between companies and chamber of commerce, engineering colleges, and so on. This factor was ranked the 14 th in importance.

With respect to the acquisition of software, the respondents were conscious of the positive effect produced by continuous training and updating of tools used in their jobs, in this case software. They classified this as the second most important factor with a significant impact on the performance of construction companies.

Moreover, the results show evidence of some changes in staff thinking in companies in the sector in favor of usage of new software in addition to the use of cloud computing and its potential benefits in networking.

The ANOVA analysis carried out in this study highlights the characteristics that generate the different perceptions of the respondents about those factors. The two categories of respondents who perceived this main component differently involved profession and age. When the profession of the respondents was characterized, statistically significant differences were detected. These differences will be analyzed in the subsequent sections.

4.2.5. External Drivers of Innovation. The grouping includes four factors: (i) public policy instruments; (ii) client influence, including requirements, competence, and level of sophistication; (iii) external influences; and (iv) construction market sources.

A possible definition of the external drivers of innovation, seen from the company's perspective, is the ability to assimilate and adopt technologies from outside the firm, such as the improvements to the design of products and the exploitation of existing technologies through technological vigilance in favor of increased productivity. It is not necessarily a question of achieving major innovations but of gaining experience and developing productive capacity by 
adapting and improving the technological knowledge obtained, in terms of both products and production processes [24].

The first factor, related to public policy instruments, refers to their effectiveness in fostering innovation in the construction industry. The challenges faced by companies in the construction sector today and about statistical and economic data analyzed generate a chain of actions at different levels, such as existing fiscal benefits for investment in R\&D and innovation [8] and the standardization of innovation processes through the UNE 166000 set of standards, one of the first in the world to offer a certifiable standardized management system for innovation.

The Spanish Ministry of Development introduced another change in this direction in 2006, allowing the final score for public tenders to be reevaluated if R\&D activities are included in the project, and for this score to be increased by between $10 \%$ and $25 \%[9,85,86]$. Also, it is important to establish improvements in the public methodologies on decision-making in infrastructure that best represent social needs [3].

Respondents in this section ranked public policy instruments in the 15th place, considering it one of the least important.

With regard to the influence of the client on the level of demand, the respondents placed this factor among the top four. This result agrees with that of Barlow, Manley, and Pellicer in that the drive for innovation arises when the clients demand results that surpass the usual level. As the client becomes more demanding and experienced, it is more likely that innovation will be driven in the relevant projects $[7,9,65]$.

Regarding external influences, it is well known that the construction sector is not a natural creator of technology; however, employing technology linked to the market will give the most positive results. In this case, the market comprises competitors or other undertakings in the same branch of activity.

4.2.6. Innovation in Processes. This construct includes two factors: (i) transfer of project learning to ongoing business practices and (ii) feedback cycles at various stages of innovation.

The transfer of project learning to ongoing business practices, especially in project-based enterprises within the sector, often presents difficulties, since the internal processes for storing and reapplying innovative ideas are weak [54].

Project communications and feedback cycles could be the key to positively impacting the performance of construction projects in terms of time and cost. In other words, collective sharing of experiences facilitates personal development and enables effective project learning.

Continuous feedback cycles of lesson learned strengthen innovation processes. Several research studies agree that innovation processes contribute to improving the commercial performance of construction firms and identify similar characteristics in their interactive models [9, 58-62]. All of these models emphasize the existence of important feedback loops between the stages of innovation, while recognizing two main types of innovation drivers: those external to the firm (environmental factors) and those internal to the firm (strategies, capabilities, and characteristics).

4.2.7. Culture of Innovation in the Company. This comprises two factors: (i) recruitment of new graduates and (ii) collaboration, cooperation, and camaraderie of staff.

A company's culture is founded on aspects such as its history and environment and is revealed in aspects such as communication and language, the system of production of materials, social and immaterial goods, interpersonal relations, leadership, and subcultures [87]. Culture can be used as a managed means of improving performance and achieving objectives [88]. The management of an organization can then formulate an internal strategy to emphasize the identification and cohesion of the members around the key values of the external strategy.

Human resources issues are essential and relate to the impact of employees in construction organizations. Likewise, leadership, which can be seen as a combination of skills and knowledge, influences and motivates workers to carry out their tasks, including issues such as negotiation processes, conflict management, and team building [31].

With regard to the factor of collaboration and cooperation of staff, the results of the survey reveal that, in order for innovation to be carried out in this area, there must be collaboration between the different levels of the organization chart. In other words, there must be participation and commitment on the part of both workers and management in the development and adaptation of technological innovation.

Table 3 (Ranking of factors) lists all of these factors according to their level of importance.

4.3. Analysis of Variance by Factor. An ANOVA is performed within each of the variables studied, in order to assess whether there are significant differences between them. It assesses the variance among groups and within groups and calculates a metric that indicates the level of significance among the variables.

With respect to the level of significance, the $P$ value determines the validity of the hypotheses. If $P>0.05$, then the average behavior of the means is equal and the hypothesis is accepted. Otherwise, the hypothesis is rejected, since there are significant differences between the categories.

The results obtained in this research are shown in Figures $2-4$.

4.3.1. Profession. The average values between the road, canal, and port engineers and staff from other professions revealed a statistically significant difference with respect to internal drivers of innovation (i) with $P=0.028$. Figure 2 shows that this difference between the perceptions of other professions means that internal drivers of innovation have a 


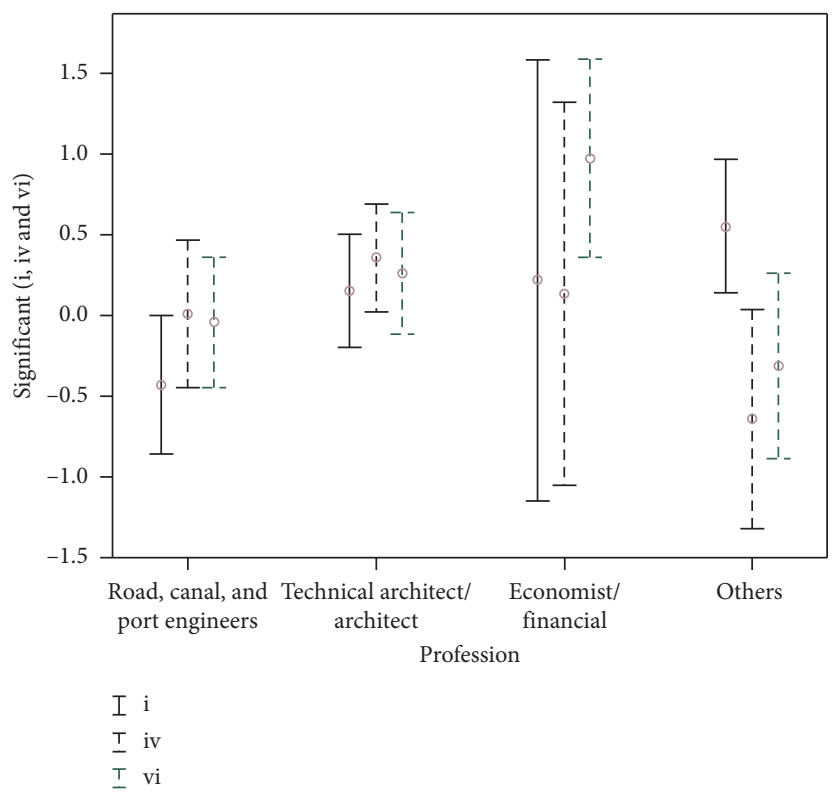

Figure 2: ANOVA internal drivers of innovation (i), technological links with the environment (iv), and innovation in processes (vi)/ profession, 95\% least significance difference (LSD). ${ }^{*}$ Note: here, "others" means the following job titles: technician, industrial engineer, environmental engineer, or accountant.

greater impact on the performance of companies than the opinions of road, canal, and port engineers.

The professions considered here are divided into five levels, as described above. Likewise, for the seven components tested, there is a statistically significant difference with a $95 \%$ confidence level between the mean values of factor (iv) (technological links with the environment), from one profession to another with $P=0.029$. On average, architects and technical architects consider that the technological links with the environment have a greater impact on the performance of the company than the other professions.

Another important aspect shows significant differences between the average values of factor relating to innovation in processes (vi) from one profession to another with $P=0.04$. Graduates in economic/financial positions within the organization consider that innovation in processes has a greater impact on the performance of the company compared to other professionals.

4.3.2. Age. The perceptions of the respondents were analyzed in regard to factor (iv), the technological links with the environment, considering the age of the respondents. This category included two ranges: 41 to 50 years old and over 51 years old. The ANOVA analysis revealed $(P=0.009)$ that respondents in the 41-50 age range believe that the technological links with the environment have a greater impact on company performance than respondents over 51 .

In this study, the age ranges are classified into four categories (see Figure 3). In this case, the two components that revealed significant differences with respect to factor (vii) (culture of innovation within the company) were the 23 - to 30 -year-old and 31 to 40 -year-old ranges. Workers

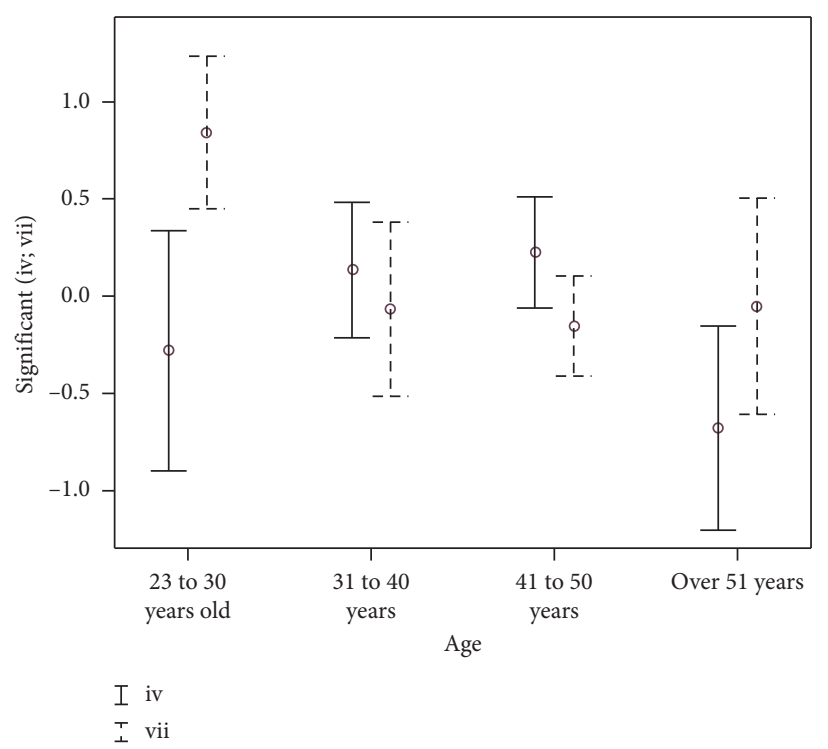

FIgURE 3: ANOVA technological links with the environment (iv), culture of innovation within the company/age, 95\% least significance difference (LSD).

between 23 and 30 years of age consider that activities that benefit the establishment of a culture prone to innovation will have a positive impact on performance, with $P=0.018$. Respondents between 31 and 50 years old consider it to have a lesser degree of impact.

4.3.3. Company Size. This subsection focuses on the perceptions of the respondents in regard to the size of the company. The ANOVA analysis showed that the two 


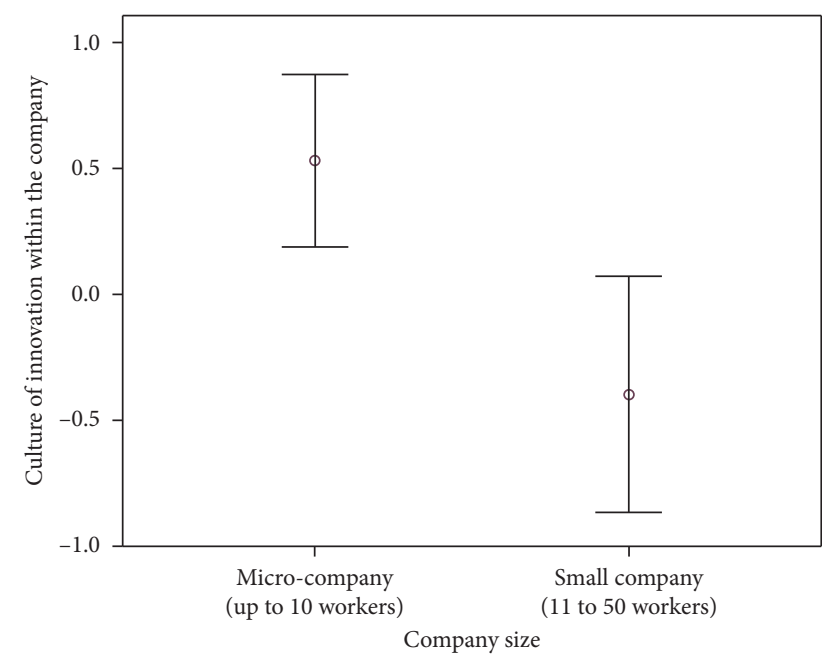

FIGURE 4: ANOVA culture of innovation within the company/ company size, 95\% least significance difference (LSD).

categories (micro- and small enterprises) differed significantly $(P=0.07)$ in their perceptions of how the implementation of an innovation culture in the company affects performance. Figure 4 shows that microenterprises consider that this factor has a greater impact on enterprise performance than small enterprises.

\section{Conclusions}

This research has studied the correlation between elements considered to be innovative and the performance of companies in the construction sector in Spain, via the application of a survey of a sample of 103 companies. The analysis results indicate that 13 out of 18 factors relating to individual, group, and organizational levels were identified to be critical factors, of which "technology and equipment" and "software acquisition" are regarded as the two most significant. In addition, the factors can be assigned into seven groupings: (i) internal drivers of innovation; (ii) innovation within the organization; (iii) technological innovation; (iv) technological links with the environment; (v) external drivers of innovation; (vi) innovation in processes; (vii) a culture of innovation in the company. Technological innovation is especially strong among the seven groupings.

The implications that have the greatest degree of impact and that can be drawn from this research are the following:

(1) Technology and equipment and software acquisition are two attractive factors when talking about innovation; however, factors such as collaboration, customer influence, and motivation are considered fundamental for innovation strategies to work and to be successful.

(2) The results show evidence of some changes in staff thinking in companies in the sector in favor of usage of new software, in addition to the use of cloud computing and its potential benefits in networking.

(3) The figure of a person responsible for R\&D\&I in a formal way and the decentralized organizations are perceived as unnecessary. This is because they are long-term strategies and if they are not put into practice, they disappear.

(4) If the aspects of $R \& D$ considered here as producers of impact on the company's profits are not systematic, they disappear and return to "informality."

(5) The microenterprises combined with the youngest employed staff (23 to 30 years) are aware of the positive impact produced by the systematic development of an innovation culture.

In this way, this study expands the existing literature on innovation, based on the theory of external and internal drivers, innovation in processes, and innovation culture within the organization in the context of the Spanish business environment, where few empirical studies have been applied to the construction sector.

Although the research provides relevant information, this paper presents a study of a small sample of construction companies, and the results cannot yet be extrapolated to the sector as a whole; however, this analysis does raise interesting considerations for future research.

As future lines of research, it is necessary to study in depth the influence that the client has on the innovation processes and the impact that they generate on the companies of the sector and on the other hand to analyze in more detail the importance of the R\&D figures on a formal way studying if there is any way that the benefits can be reflected in the short or medium term to stimulate the innovation in a permanent way in the sector.

\section{Data Availability}

The data used to support the findings of this research are available from the corresponding author upon request.

\section{Conflicts of Interest}

The authors declare no conflicts of interest.

\section{Acknowledgments}

This research was funded by the Spanish Ministry of Economy and Competitiveness, along with FEDER, Grant no. BIA2017-85098-R.

\section{References}

[1] C. Torres-Machí, A. Carrión, V. Yepes, and E. Pellicer, "Employability of graduate students in construction management," Journal of Professional Issues in Engineering Education and Practice, vol. 139, no. 2, pp. 163-170, 2013.

[2] Free College of Emeritus, The Construction Sector in Spain: Analysis, Perspectives and Proposals, Free College of Emeritus, Boadilla del Monte, Spain, 2010.

[3] L. A. Sierra, V. Yepes, and E. Pellicer, "A review of multicriteria assessment of the social sustainability of infrastructures," Journal of Cleaner Production, vol. 187, pp. 496-513, 2018.

[4] M. J. Herrero, J. I. Escavy, and M. Bustillo, "The Spanish building crisis and its effect in the gypsum quarry production 
(1998-2012)," Resources Policy, vol. 38, no. 2, pp. 123-129, 2013.

[5] O. Industrial de la Construcción, Informe sobre el sector de la construcción, 2018, in Spanish.

[6] I. J. Navarro, V. Yepes, and J. V. Martí, “A review of multicriteria assessment techniques applied to sustainable infrastructure design," Advances in Civil Engineering, vol. 2019, Article ID 6134803, 16 pages, 2019.

[7] K. Manley, "The innovation competence of repeat public sector clients in the Australian construction industry," Construction Management and Economics, vol. 24, no. 12, pp. 1295-1304, 2006.

[8] E. Pellicer, C. L. Correa, V. Yepes, and L. F. Alarcón, “Organizational improvement through standardization of the innovation process in construction firms," Engineering Management Journal, vol. 24, no. 2, pp. 40-53, 2012.

[9] E. Pellicer, V. Yepes, C. L. Correa, and L. F. Alarcón, "Model for systematic innovation in construction companies," Journal of Construction Engineering and Management, vol. 140, no. 4, Article ID B4014001, 2014.

[10] Organisation for Economic Co-Operation and Development, A New Economy?: The Changing Role of Innovation and Information Technology in Growth, OECD Publishing, Paris, France, 2000.

[11] E. Viaña, "Innovación no sólo es tecnología," Expansión, p. 52, 2018 in Spanish.

[12] A. Pérez-Luño, J. Wiklund, and R. V. Cabrera, "The dual nature of innovative activity: how entrepreneurial orientation influences innovation generation and adoption," Journal of Business Venturing, vol. 26, no. 5, pp. 555-571, 2011.

[13] Instituto Nacional de Estadística y Censos, ENIT Encuesta Nacional Sobre Innovación y Conducta: ENIT 2005, Instituto Nacional de Estadística y Censos, Buenos Aires, Argentina, in Spanish, 1st edition, 2008.

[14] M. De Oslo, Guía Para la Recogida e Interpretación de Datos Sobre Innovación, OECD, Luxembourg, in Spanish, 2005.

[15] P. F. Drucker, Managing in the Next Society, Routledge, London, UK, 2013.

[16] D. Chudnovsky, A. Lopez, and G. Pupato, Innovation and Productivity: A Study of Argentine Manufacturing Firms' Behavior (1992-2001), Universidad de San Andres, Buenos Aires, Argentina, 2004.

[17] J. A. De Negri, M. S. Salerno, and A. Barros de Castro, Innovations, Technological Standards and Performance of Brazilian Industrial Firms, 2005.

[18] B. Tether and G. M. P. Swann, Sourcing Science: The Use by Industry of the Science Base for Innovation; Evidence from the UK's Innovation Survey, Centre for Research on Innovation and Competition, University of Manchester, Manchester, UK, 2003.

[19] D. Suarez, "Dinámica innovativa y estructura de vinculaciones en la industria manufacturera Argentina," in Proceedings of the XII Seminario Latino-Iberoamericano de Gestion Tecnológica (ALTEC 2007), Buenos Aires, Argentinain Spanish, Buenos Aires, Argentina, September 2007.

[20] J. Fagerberg and B. Verspagen, "Technology-gaps, innovation-diffusion and transformation: an evolutionary interpretation," Research Policy, vol. 31, no. 8-9, pp. 1291-1304, 2002.

[21] R. G. M. Kemp, J. P. J. de Jong, M. Folkeringa, and E. F. M. Wubben, "Innovation and firm performance: differences between small and medium-sized firms," in Proceedings of the Paper presented at the Annual International
SMS-conference on Intersections: Strategy across Conventional Boundaries, SMS, Baltimore, MD, USA, 2003.

[22] B. Kosacoff and N. U. Cepal, Estrategias Empresariales en Tiempos de Cambio: el Desempeño Industrial Frente a Nuevas Incertidumbres, Universidad Nacional de Quilmes, Bernal, Argentina, in Spanish, 1998.

[23] S. Lall, "Reinventing industrial strategy: the role of government policy in building industrial competitiveness," Annals of Economics and Finance, vol. 14, no. 2, pp. 785-829, 2013.

[24] G. Lugones, Módulo de Capacitación Para la Recolección y el Análisis de Indicadores de Innovación, vol. 8, Banco Interamericano de Desarrollo, Washington, DC, USA, 2008, in Spanish.

[25] B.-A. Lundvall, National Innovation Systems, Pinter, London, UK, 1992.

[26] J. A. Ocampo, Beyond Reforms: Structural Dynamics and Macroeconomic Vulnerability, The World Bank, Washington, DC, USA, 2005.

[27] E. S. Reinert, The Role of Technology in the Creation of Rich and Poor Nations: Underdevelopment in a Schumpeterian System, Universidad ESAN, Lima, Peru, 2017.

[28] L. A. Sierra, E. Pellicer, and V. Yepes, "Method for estimating the social sustainability of infrastructure projects," Environmental Impact Assessment Review, vol. 65, pp. 41-53, 2017.

[29] A. M. Blayse and K. Manley, "Key influences on construction innovation," Construction Innovation, vol. 4, no. 3, pp. 143154, 2004.

[30] A. L. Castro, V. Yepes, E. Pellicer, and A. J. Cuéllar, "Knowledge management in the construction industry: state of the art and trends in research," Revista de la Construcción, vol. 11, no. 3, pp. 62-73, 2012.

[31] V. Yepes, E. Pellicer, and A. J. Ortega, "Designing a benchmark indicator for managerial competences in construction at the graduate level," Journal of Professional Issues in Engineering Education and Practice, vol. 138, no. 1, pp. 48-54, 2012.

[32] D. C. North, Institutions, Institutional Change and Economic Performance, Cambridge University Press, Cambridge, UK, 1990.

[33] E. H. Schein and P. Schein, Organizational culture and leadership (5th Edition), Vol. 4, Wiley, Hoboken, NJ, USA, 2017.

[34] S. Kivrak, A. Ross, and G. Arslan, "Impacts of cultural differences on knowledge management practices in construction," in Proceedings of the Fifth International Conference on Construction in the 21st Century (CITC-V): Collaboration and Integration in Engineering, Management and Technology, pp. 20-22, Istanbul, Turkey, May 2009.

[35] M. D. Kull, "Scaling the water cooler: digital storytelling for knowledge continuity," The Story of Managing Projects: A Global, Crossdisciplinary Collection of Perspectives, pp. 106117, Praeger, Westport, CT, USA, 2005.

[36] V. A. G. Castillo and R. B. Walker, "Innovación tecnológica en la construcción ahora es cuando," Revista Ingeniería de Construcción, no. 14, pp. 9-18, 2012, in Spanish.

[37] I. L. S. A. Massa and E. T. Alarcón, Innovación y Creatividad en la Empresa un Acercamiento Práctico, Publicaciones de la Universidad de Alicante, Alicante, Spain, in Spanish, 2008.

[38] R. Pampillón, "El mercado laboral frena su mejoría," Expansión, pp. 20-21, 2019, in Spanish.

[39] Cotec, Fundación Cotec para la Innovación, Informe Cotec, Madrid, Spain, 2018, http://informecotec.es/media/InformeCotec_2018_versiónweb.pdf. 
[40] J. B. Barney, "Firm resources and sustained competitive advantage," in Economics Meets Sociology in Strategic Management, pp. 203-227, Emerald Group Publishing Limited, Bingley, UK, 2000.

[41] S. Villoria and Á. C. García, "El papel de la empresa en la competitividad," Papeles de Economía Española, no. 56, pp. 363-378, 1993, in Spanish.

[42] B. P. Mishra and R. Srinivasan, "A framework for technology innovation," Journal of Advances in Management Research, vol. 2, no. 1, pp. 61-69, 2005.

[43] P. K. Ahmed, "Culture and climate for innovation," European Journal of Innovation Management, vol. 1, no. 1, pp. 30-43, 1998.

[44] W. Enegbuma, G. Aliagha, and K. Ali, "Preliminary building information modelling adoption model in Malaysia," Construction Innovation, vol. 14, no. 4, pp. 408-432, 2014.

[45] N. Anderson, K. Potočnik, and J. Zhou, "Innovation and creativity in organizations: a state-of-the-science review, prospective commentary, and guiding framework," Journal of Management, vol. 40, no. 5, pp. 1297-1333, 2014, in Spanish.

[46] T. Ercan, "Investigation of the effects of innovation areas on organizational performance in production companies," Megaron, vol. 11, no. 2, 2016.

[47] F. Schultmann and N. Sunke, "Closed-loop oriented project management in construction: an approach for sustainable construction management," in Proceedings of the Conference Rethinking Sustainable Construction 2006, Tampa, FL, USA, September 2006.

[48] M. Ball, Rebuilding Construction (Routledge Revivals): Economic Change in the British Construction Industry, Routledge Revivals, Abigdon, UK, 2014.

[49] C. Lusthaus, M. Adrien, G. Anderson, F. Carden, and G. Montalvan, Evaluación Organizacional, BID, Washington, DC, USA, in Spanish, 2002.

[50] D. Craig and R. Roy, Developing a Customer Service Culture in the Speculative Housebuilding Industry, Warwick Manufacturing Group, University of Warwick, Coventry, UK, 1999.

[51] J. N. Lim and G. Ofori, "Classification of innovation for strategic decision-making in construction businesses," Construction Management and Economics, vol. 25, no. 9, pp. 963-978, 2007.

[52] S. Groak, The Idea of Building: Thought and Action in the Design and Production of Buildings, E \& FN Spon, London, UK, 2002.

[53] National Research Council of Canada, "Construction innovation: opportunities for better value and profitability," in Proceedings of the International Symposium of Construction Innovation, Ottawa, Canada, June 2001.

[54] D. M. Gann and A. J. Salter, "Innovation in project-based, service-enhanced firms: the construction of complex products and systems," Research Policy, vol. 29, no. 7-8, pp. 955-972, 2000.

[55] INE, Encuesta Sobre Innovación en las Empresas, INE, Mexico City, Mexico, in Spanish, 2016.

[56] F. Y. Y. Ling, "Managing the implementation of construction innovations," Construction Management and Economics, vol. 21, no. 6, pp. 635-649, 2003.

[57] G. Seaden and A. Manseau, "Public policy and construction innovation," Building Research \& Information, vol. 29, no. 3, pp. 182-196, 2001.

[58] G. Winch, "Zephyrs of creative destruction: understanding the management of innovation in construction," Building Research \& Information, vol. 26, no. 5, pp. 268-279, 1998.
[59] G. Seaden, M. Guolla, J. Doutriaux, and J. Nash, "Strategic decisions and innovation in construction firms," Construction Management and Economics, vol. 21, no. 6, pp. 603-612, 2003.

[60] M. Sexton and P. Barrett, "A literature synthesis of innovation in small construction firms: insights, ambiguities and questions," Construction Management and Economics, vol. 21, no. 6, pp. 613-622, 2003.

[61] K. Manley, S. McFallan, M. Swainston, and S. Kajewski, "Assessing the value of different business strategies to innovation by firms in the construction industry," in Proceedings of the 2008 4th IEEE International Conference on Management of Innovation and Technology, pp. 588-593, Bangkok, Thailand, September 2008.

[62] A. Hartmann, "The context of innovation management in construction firms," Construction Management and Economics, vol. 24, no. 6, pp. 567-578, 2006.

[63] P. M. Goodrum and C. T. Haas, "Partial factor productivity and equipment technology change at activity level in U.S. construction industry," Journal of Construction Engineering and Management, vol. 128, no. 6, pp. 463-472, 2002.

[64] C. H. Nam and C. B. Tatum, "Leaders and champions for construction innovation," Construction Management and Economics, vol. 15, no. 3, pp. 259-270, 1997.

[65] J. Barlow, "Innovation and learning in complex offshore construction projects," Research Policy, vol. 29, no. 7-8, pp. 973-989, 2000.

[66] M. Kumaraswamy and M. Dulaimi, "Empowering innovative improvements through creative construction procurement," Engineering, Construction and Architectural Management, vol. 8 , no. 5/6, pp. 325-334, 2001.

[67] R. Gulezian and F. Samelian, "Baseline determination in construction labor productivity-loss claims," Journal of Management in Engineering, vol. 19, no. 4, pp. 160-165, 2003.

[68] A. S. Hanna, C. S. Taylor, and K. T. Sullivan, "Impact of extended overtime on construction labor productivity," Journal of Construction Engineering and Management, vol. 131, no. 6, pp. 734-739, 2005.

[69] P. Barrett, "A global agenda for revaluing construction: the client's role," Clients Driving Innovation, Wiley-Blackwell, Oxford, UK, 2008.

[70] T. Peters and N. Austin, A Passion for Excellence: The Leadership difference, Random House, New York, NY, USA, 1985.

[71] J. B. Quinn, "Managing innovation: controlled chaos," Harvard Business Review, vol. 63, no. 3, pp. 73-84, 1985.

[72] P. G. Santamaría, D. E. Vázquez, and D. M. Domínguez, Influencia del Valor Percibido y de la Satisfacción en la Lealtad: una Aplicación al Turismo Náutico, University of Vigo, Vigo, Spain, in Spanish, 2015.

[73] J. C. Nunnally, Psychometric Theory: 2nd Edition, McGrawHill, New York, NY, USA, 1978.

[74] Y. Xu, J. F. Y. Yeung, A. P. C. Chan, D. W. M. Chan, S. Q. Wang, and Y. Ke, "Developing a risk assessment model for PPP projects in China-a fuzzy synthetic evaluation approach," Automation in Construction, vol. 19, no. 7, pp. 929-943, 2010.

[75] X. Zhao, B.-G. Hwang, S. Pheng Low, and P. Wu, "Reducing hindrances to enterprise risk management implementation in construction firms," Journal of Construction Engineering \& Management, vol. 141, no. 3, Article ID 04014083, 2014.

[76] E. R. Pérez and L. Medrano, "Análisis factorial exploratorio: bases conceptuales y metodológicas," Revista Argentina de Ciencias del Comportamiento, vol. 2, no. 1889, pp. 58-66, 2010, in Spanish. 
[77] J. F. Hair, R. E. Anderson, R. L. Tatham, and W. C. Black, Análisis Multivariante, Vol. 491, Prentice Hall, Madrid, Spain, 1999.

[78] I. Mavrou, "Análisis factorial exploratorio: cuestiones conceptuales y metodológicas," Revista Nebrija de Lingüística Aplicada a la Enseñanza de Lenguas, Universidad Antonio de Nebrija, Manzanares, Spain, in Spanish, 2015.

[79] A. L. Comrey and H. B. Lee, A First Course in Factor Analysis, Psychology Press, Hove, UK, 2013.

[80] F. Damanpour, "Organizational complexity and innovation: developing and testing multiple contingency models," Management Science, vol. 42, no. 5, pp. 693-716, 1996.

[81] S. Y. W. Lam and C. H. W. Tang, "Motivation of survey employees in construction projects," Journal of Geospatial Engineering, vol. 5, no. 1, pp. 61-66, 2003.

[82] G. Naranjo, E. Pellicer, and V. Yepes, "Marketing in the construction industry: state of knowledge and current trends," Dyna-Colombia, vol. 78, no. 170, pp. 245-253, 2011.

[83] P. Shrivastava and W. E. Soulder, "Phase transfer models for technological innovation," Advances in Strategic Management, vol. 3, pp. 135-147, 1985.

[84] L. A. Sierra, V. Yepes, T. García-Segura, and E. Pellicer, "Bayesian network method for decision-making about the social sustainability of infrastructure projects," Journal of Cleaner Production, vol. 176, pp. 521-534, 2018.

[85] C. L. Correa, V. Yepes, and E. Pellicer, "Factores determinantes y propuestas para la gestión de la innovación en las empresas constructoras," Revista Ingeniería de Construcción, vol. 22, no. 1, pp. 5-14, 2007, in Spanish.

[86] E. Pellicer, V. Yepes, C. Correa, and G. Martínez, "Enhancing R\&D\&i through standardization and certification: the case of the Spanish construction industry," Revista Ingeniería de Construcción, vol. 23, no. 2, pp. 112-121, 2011.

[87] A. Z. Dominguez and A. R. Ramirez, Gestion de la Cultura Organizacional: Bases Conceptuales Para su Implementacion, University of Valle, Cali, Colombia, in Spanish, 2008.

[88] L. Smircich, "Concepts of culture and organizational analysis," Administrative Science Quarterly, vol. 28, no. 3, pp. 339-358, 1983. 